\title{
Conceito de rede e as sociedades contemporâneas
}

The concept of network and the contemporary societies

\author{
Ana Lucia S. Enne \\ Prfa. Dra. do Departamento de Antropologia da UFR). \\ E-mail: anaenne@terra.com.br
}

Resumo

A proposta deste artigo é mapear algumas das principais abordagens referentes ao conceito de rede, muito utilizado nas reflexões sobre as sociedades contemporâneas. 0 conceito é apresentado em sua relação com os fluxos de bens e informações, a partir das práticas de interação social.

Palavras-chave: rede; fluxo de informação; sociedades contemporâneas

Introdução

' BARNES, J. A. "Redes sociais e processo político". In: FELDMANBIANCO, Bela (org.). Antropologia das Sociedades Contemporâneas. São Paulo, Global, 1987

${ }^{2}$ Esse trabalho é citado pelo próprio Barnes, no texto já citado. A referência é: BARNES, J.A. "Class and Committees in a Norwegian Island Parish". Human Relations, $n^{\circ} 7,1964$

${ }^{3}$ MAYER, Adrian. "A importância dos 'quase-grupos' no estudo das sociedades complexas". In: FELDMANBIANCO, op. cit., 1987, p. 129. 0 trabalho de FIRTH a que ele se refere é "Social Organization \& Social Change", Journal of the Royal Anthopological Institute, $n^{\circ} 84,1954$. Sobre o papel de Radcliffe-Brown como pioneiro no uso do termo rede para pensar relações sociais, ver também BOT, Elizabeth. Familia e Rede Social. Rio de Janeiro, Francisco Alves, 1976 , p. 294
Lugar comum nas análises da sociedade contemporânea, o conceito de rede tem sido muito empregado para definir as novas formas de socialização e fluxo informacional dentro da chamada ordem globalizada. No entanto, tal conceito vem sendo trabalhado de formas distintas dentro das Ciências Sociais, em especial na Antropologia e na Comunicaçăo, e essa multiplicidade conceitual nem sempre é levada em conta. A proposta deste artigo é mapear algumas das principais abordagens referentes a essa categoria, procurando dar conta das possibilidades teóricas geradas por esse conceito para descrever determinados tipos de relações sociais.

\section{Redes como sistemas de interação social}

O conceito de rede é pensado, muitas vezes, como um tipo de sistema de inter-relação social diferente do grupo, por diversas características. Os autores que agora apresentaremos, considerados clássicos nas Ciências Sociais por suas propostas de teorização do conceito, vão desfilar tais características e, mesmo com alguns pontos divergentes, irăo convergir no principal aspecto definidor do que seria uma rede: sua capacidade de articulação $\mathrm{e}$ rearticulação permanente.

$\mathrm{Na}$ década de 60, J. A. Barnes, em seu artigo "Redes sociais e processo político", 1 procura ampliar as explicaçōes acerca do conceito de rede já utilizado por ele em um trabalho anterior sobre uma comunidade da Noruega, ${ }^{2}$ e que, segundo o autor, teria padecido de uma falta de definição conceitual geradora de interpretaçốes confusas por parte de alguns leitores/pesquisadores. Assim, ele vai tentar indicar que a idéia de rede utilizada em seu trabalho está, antes de tudo, pensada como socialmente composta por indivíduos que irão se articular a partir de interaçôes, e não por composiçōes egocêntricas, como irão propor outros. A rede com a qual trabalharia seria, portanto, a rede social total.

$\mathrm{O}$ que Barnes se propôs a fazer - e nesse sentido é percebido como um precursor no uso do conceito de rede para pensar analiticamente determinados contextos sociais em que a idéia de grupo não pareceria adequada - é transpor o conceito simbólico de rede, como utilizado primeiramente por Radcliffe-Brown, para usá-lo analiticamente, como instrumento metodológico de compreensão de relaçốes sociais entre indivíduos. Assim, RadcliffeBrown teria pensado o conceito de rede como uma simbologia para entender a estrutura social. Rede estaria, dessa forma, ligada a situaçóes de permanência, e năo a articulaçóes temporárias. Segundo explica Mayer, citando Firth, "Radcliffe-Brown usou a noção de rede para expressar de modo impressionista "o que sentia ao descrever metaforicamente o que via", cabendo a Barnes dar ao termo uma definição mais precisa".

Barnes prefere falar de dois tipos de rede: "redes sociais totais" e "redes sociais parciais". Sobre as primeiras, ele afirma: 
Quer a rede possa ou não ser associada de maneira útil à estrutura social, não podemos encontrá-la nem aqui nem ali. Independentemente de qualquer coisa, a rede é uma abstração de primeiro grau da realidade, e contém a maior parte possível da informação sobre a totalidade da vida social da comunidade à qual corresponde. Chamo-a de rede social total. ${ }^{4}$

Quanto às redes parciais, seriam "qualquer extração de uma rede total, com base em algum critério que seja aplicável à rede total". 5 Assim, por sua proposta, qualquer indivíduo (que ele irá trabalhar genericamente como Alfa) dentro de uma rede pode ser tomado como referência para pensar a sua composição, e não um ego em especial. A partir de um Alfa qualquer, seria possível medir graus de associação entre os componentes de uma rede, cuja grandeza poderia ser medida a partir da metáfora de uma constelação. Ou seja, os indivíduos que estivessem em relação direta seriam estrelas de uma ordem de primeira grandeza, enquanto aqueles que não fossem diretamente ligados a Alfa, mas estivessem ligados a um agente diretamente a ela relacionado (por exemplo, Beta), poderiam ser acionados para um contato através da intermediaçāo de Beta. Seriam, então, de uma ordem de segunda grandeza. Uma rede seria, portanto, uma construção social de relaçôes de grandezas distintas, mas que possibilitariam o contato entre os diversos elementos que iriam gerar sua composição (por exemplo, parentesco, vizinhança, laços políticos, dentre outros). Esse conceito de rede poderia ser aplicado para diversos estudos sociais, sendo útil

na descrição e análise de processos políticos, classes sociais, relação entre um mercado e sua periferia, provisão de serviços e circulação de bens e informaçōes num meio social nãoestruturado, manutençáo de valores e normas pela fofoca, diferenças estruturais entre sociedades tribais, rurais e urbanas, e assim por diante. ${ }^{6}$

O trabalho do pesquisador, ao etnografar as redes, deveria ser também, com o apoio de teorias matemáticas, o de

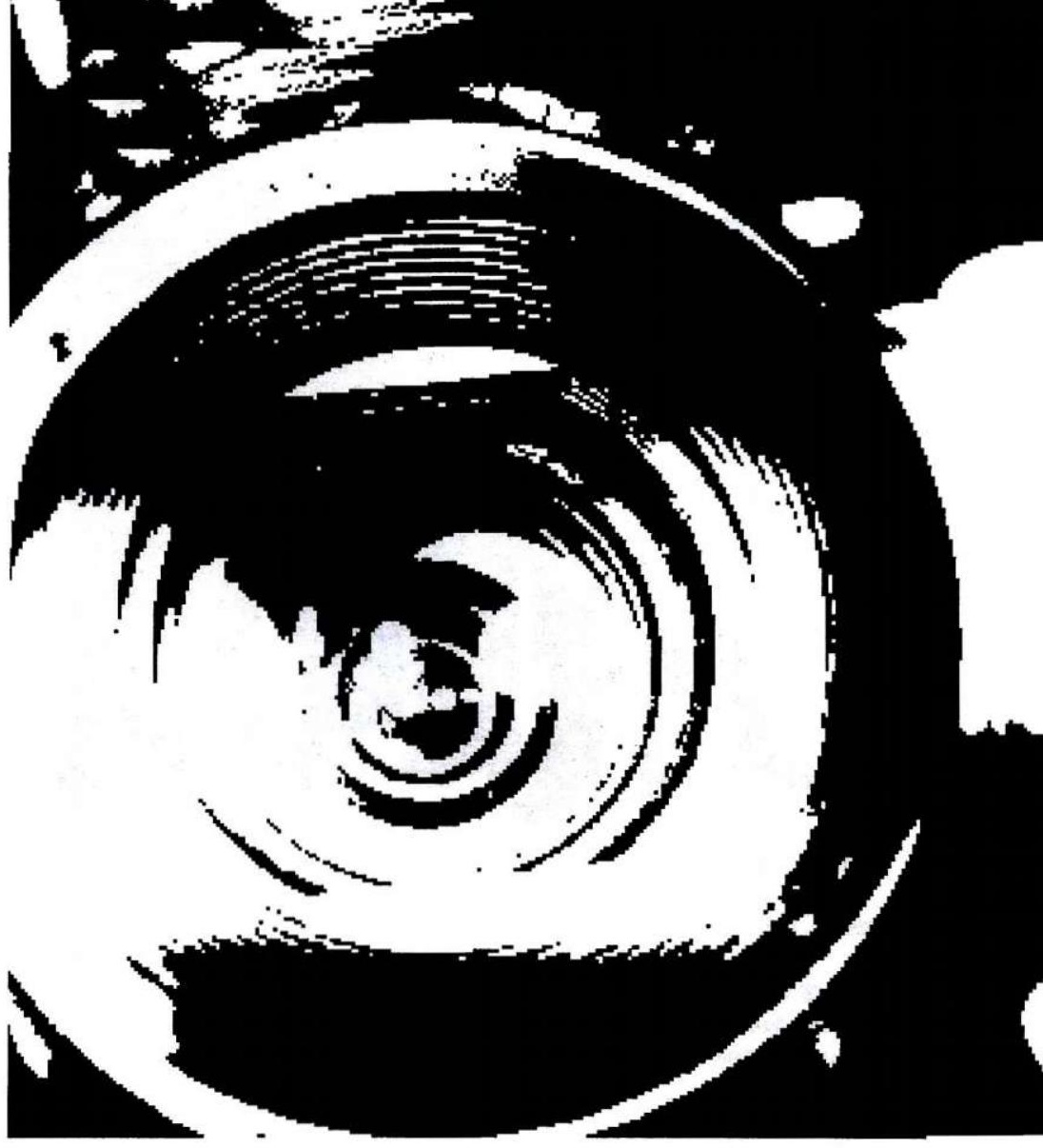

medir a densidade das relaçôes entre as estrelas e suas grandezas, em termos de conexão. Segundo ele, o correto seria definir "esta medida, a densidade da zona, como sendo a proporção das linhas diretas, teoricamente possíveis, que de fato existem" entre as diversas estrelas que compóem uma rede. Por isso, questōes como a finitude ou o limite da rede ocupariam posiçóes de destaque nos seus trabalhos. Mas, independentemente da densidade de uma rede, o estudo das redes parciais levaria, necessariamente, à compreensão da rede total. ${ }^{7}$

Mayer vai partir da formulação do conceito de rede por Barnes - e também por Bott - e propor uma distinção dessa categoria face a de conjunto, por achar que o termo rede, usado para todos os contextos de interação, não permite uma depuração dos diversos níveis de contato. Assim, para Mayer, rede deveria ser pensada de forma mais abrangente, como algo ilimitado e que correspondesse à estrutura social (no sentido proposto por Radcliffe-Brown). Já o termo conjunto (derivado de action-set, conjunto-de-açóes) seria mais adequado para pensar situaçôes de contato também sugere que, ao estudar uma parte da rede, o pesquisador seja capaz de compreender a lógica da rede de forma mais ampla. Mas ele sugere o termo "web" para substituir as idéias de "estrela" e "grandeza" propostas por Barnes. Cf. LANDÉ, Carl. "Introduction: the dyadic basis of clientelism". In: SCHMIDT, Steffen et alii (ed.). Friends, Followers, and Factions. $A$ reader in political clientelism. Berkeley, University of California Press, 1977, p.xxxiii.

${ }^{5}$ BARNES, idem, p. 166 .

${ }^{6} / d e m$, p. 161.

7 Segundo Barnes, "se examinarmos uma rede qualquer, quer seja limitada ou ilimitada, finita ou infinita, total ou parcial, e concentrarmos nossa atenção numa pessoa particular como ponto de referência, descobriremos as várias propriedades egocêntricas da rede. Isto é bastante diferente do que simplesmente dizer que a rede em $\mathrm{si}$ mesma é egocêntrica: ela não o é." Idem, p. 180.
${ }^{4}$ BARNES, op. cit., p. 166. Carl Landé 


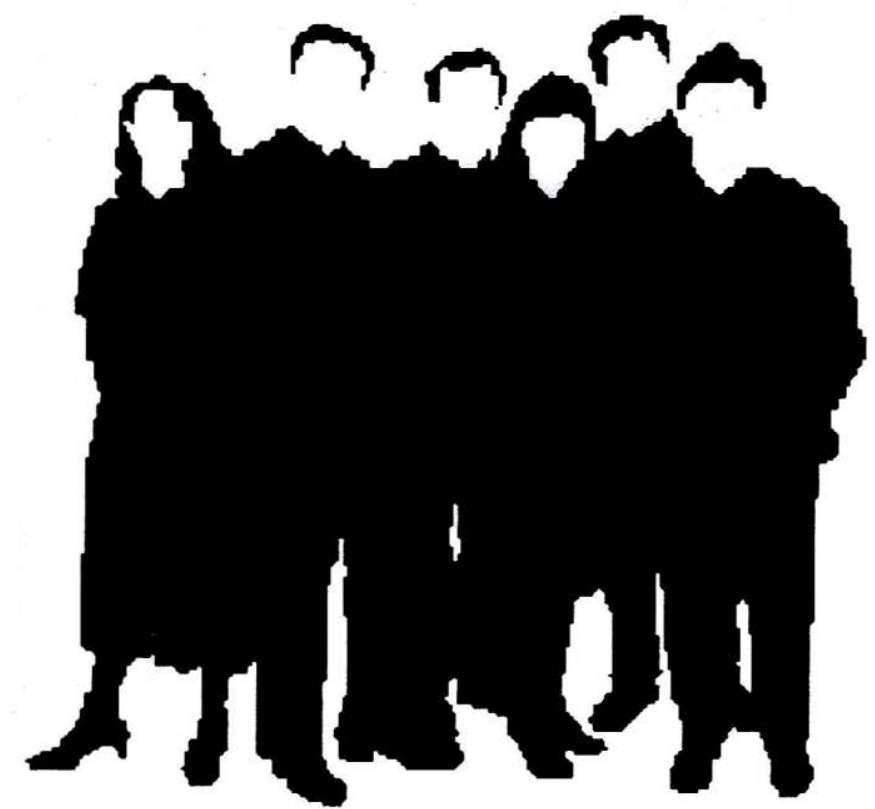

${ }^{8}$ MAYER, op. cit, p. 127.

9 Idem, p. 128.

${ }^{10} \mathrm{~B} 0 T$, op. cit. 0 texto a que me refiro é "A História do Conceito de Rede desde 1957", presente na obra citada. conjunturais, que aconteceriam em determinadas situações (um pleito eleitoral, por exemplo), criando uma série de relações, mas sem caráter necessariamente permanente. Ele vai procurar mostrar como esses conjuntos-deação configurariam quase-grupos, ou melhor, indivíduos articulados por interesses comuns a partir de um ego, mas que não poderiam ser pensados como grupos não só por seu caráter aberto (típico das redes), mas pela ausência de características típicas de um grupo, que seria constituído "por um número determinado de membros que mantêm alguma forma de interação esperada entre si - quando não em termos de direitos e obrigaçóes"8. Para ele, parte dos estudos sobre redes sociais deveria ser o estudo dos quase-grupos que, em conjuntos-de-açōes, estão sendo montados mediante relações diretas ou subjacentes, as quais denomina de laterais (contatos entre os respondentes de um determinado ego, os quais mantêm relaçóes também entre eles, sem necessariamente passar pela figura deste).

Assim, para ele, o conceito de rede proposto por Barnes serviria mais para situaçōes permanentes, não sendo adequado para contextos de conjunções momentâneas, ainda que algumas pudessem, posteriormente, adquirir um caráter mais permanente (por exemplo, um determinado período eleitoral faz surgir uma série de relaçōes entre indivíduos que, posteriormente, poderiam fundar um partido político). $\mathrm{O}$ ideal, para esses casos, seria o conceito já citado de quase-grupos, que surgiriam em conjuntos-de-açāo específicos. É importante notar que Mayer sugere duas categorias de quase-grupos. Uma primeira, dos quase-grupos classificatórios, em que "a classificaçäo, aqui, poderia ser feita em função de interesses comuns que estão subjacentes ao que poderíamos chamar de 'grupo potencial'." A outra, dos quasegrupo interativos, seria baseada em "um conjunto de indivíduos em interação". É com esta que Mayer pretende trabalhar, definindo assim os quase-grupos:

Estes quase-grupos diferem fundamentalmente do grupo e da associação. Em primeiro lugar, estão centrados em um ego, no sentido de que sua própria existência depende de um indivíduo específico como foco organizador central: é diferente de um grupo, onde a organização pode ser difusa. Em segundo lugar, as açōes de qualquer membro tornam-se relevantes apenas na medida em que são interaçōes com o próprio ego ou seu intermédio. $\mathrm{O}$ critério de associatividade não inclui a interação com outros membros do quase-grupo em geral. ${ }^{9}$

Bott, ao historiografar o conceito de rede em um texto bastante esclarecedor, ${ }^{10}$ sugere que o termo quasegrupo proposto por Mayer (na sua acepção, um novo nome para o termo agrupamento) resolve alguns problemas de denominação - principalmente por substituir este último termo -, mas acaba se mostrando "obscuro" quando se prende à idéia de que o quase-grupo seria resultado necessariamente de conjuntosde-açōes. Ela cita o uso, por exemplo, que Boisseivan faz da categoria de quase-. grupo, que seria "um termo genérico para qualquer espécie de coalizão recrutada a partir de rede. Pode ser um conjunto-deação, uma facção ou uma clique (...)". Assim, ela, como Barnes, opta pelo conceito de rede para tratar de redes totais ou parciais, afirmando que, em sua tese 
sobre famílias e relaçóes de parentesco, "as famílias, como totalidades sociais, não estavam contidas em grupos organizados mas, somente, em redes". ${ }^{11}$

Segundo Bott, a pluralidade de formulaçóes utilizadas para se pensar o conceito de rede não invalida o seu uso, mas requer uma reflexão acerca das diversas apropriaçóes que o termo tem gerado. Assim, o conceito de rede tem tido, segundo as observaçóes da autora, três acepçōes: uma primeira, mais metafórica, na já citada referência a Radcliffe-Brown; uma segunda, no sentido de rede total, sugerido por Barnes; e uma terceira, em que a rede é pensada como sendo "pessoal" ou "egocêntrica”, como proposto, por exemplo, por Mayer. Assim, "praticamente todos" - incluindo a própria Bott -, "com exceção de Barnes", estariam usando tanto o conceito de rede total quanto o de rede egocêntrica nos seus diversos estudos. ${ }^{12}$

Segundo Elizabeth Bott, o conceito de rede é fundamental em situaçóes em que a categoria grupo não consegue dar conta da complexa mobilidade entre os sujeitos que estão se relacionando socialmente. Assim, em seu estudo sobre famílias e laços de parentesco, ela resolve adotar o conceito por considerá-lo metodologicamente adequado. $^{13}$

Mitchell, também em um texto que contribuiu enormemente para organizar o debate acerca do conceito de rede, destaca a importância do trabalho desenvolvido por Bott, mas lamenta que a apropriação de Bott, associando o conceito de rede ao estudo das composiçóes familiares, tenha, por um período, se cristalizado como a referência predominante sobre o uso do conceito, limitando-o. ${ }^{14}$ Para resolver tal problema, ele irá propor, juntamente com outros autores, como Epstein, que o conceito possa ser relacionado também a diversas outras situaçóes características de sociedades complexas e urbanas. De certa forma, a própria Elizabeth Bott procurou deixar bem claro que o conceito de rede, utilizado no seu caso para o estudo de relações familiares, deveria ser pensado como associado a qualquer sistema de relaçôes sociais, citando o próprio Barnes como tendo repensado o seu conceito original e concluído que "as redes atravessam todos os campos sociais". ${ }^{15}$

\section{Redes como fluxos de mercadoria e informação}

Sugerindo a utilização do conceito de rede para o estudo de sociedades complexas e urbanas, Mitchell vai apontar para a existência de dois tipos de redes: uma envolvendo a troca de bens e serviços, e outra englobando a troca de informações, sendo esta segunda um processo de comunicação. Assim, comentando essa segunda propriedade das redes, Mitchell afirma que:

So far sociologists who have used the notion of personal networks to analyse their field material have done so in relation of two different problems. The first of these relates of the flow of communication through networks, especially in relation to the definition of norms, in what we might call a communication-set. ${ }^{16}$

Também A. L. Epstein vai utilizar essa idéia de pensar a rede como um sistema de trocas de informaçóes, capaz de gerar padróes normativos para as condutas dos grupos e, conseqüentemente, padrōes de identificação, em seus estudos urbanos. Essa apropriaçáo é explicitada por Mitchell, ao referir-se a Epstein, ${ }^{17}$ mas pode ser percebida mais claramente na leitura que fazemos do texto do próprio Epstein, quando ele aponta para a importância das configuraçóes da rede em termos de seus fluxos comunicacionais, no sentido de gerar prestígio entre os agentes que a compóem. Assim, ele afirma que toda relação social envolve a idéia de troca, e cabe ao pesquisador mapear quais são os tipos de informação que são trocadas por meio de práticas imagéticas e discursivas. ${ }^{18}$

Epstein vai utilizar a proposta de Bott de dividir as redes sociais em "abertas" ou "fechadas", de acordo com o estreitamento ou a frouxidão dos laços

\section{"Idem, p. 67. \\ $12 / d e m$, p. 300. \\ 13 “ .... a idéia de rede é necessária porque o conceito familiar de grupo e de grupo corporativo da antropologia tradicional não era inteiramente adequado para os dados de campo com os quais eu estava lidando. As famílias pesquisadas não viviam em grupos. Elas "viviam" em redes, se é que podemos usar o termo "viviam em" para descrever a situação de estar em contato com um conjunto de pessoas e organizações, algumas das quais estavam em contato umas com as outras, ao passo que outras não estavam." Idem, p. 294.}

${ }^{14}$ Afirma Mitchell: "This striking and stimulating study should have the effect of associating the notion of social networks almost exclusively with conjugal roles". Cf. MITCHELL,

op. cit., p. 6.

${ }^{15}$ B0TT, op. cit., p. 303. Grifo da autora.

${ }^{16} / d$ dem, p. 37.

${ }^{17} / d e m$, p. 27. "The flow of information is also the point that Epstein selects as the aspect of the personal network to emphasize in his study of networks in towns", indica Mitchell. 
${ }^{18}$ EPSTEIN, A. L. "Gossip, norms and social network". In: FELDMAN-BIANCO, op. cit., p. 124.

${ }^{19}$ No caso da "Baixada Fuminense", este me parece um aspecto bem rico para pensarmos a formação de uma rede de memória e história, como demonstrei em minha tese de doutorado. Cf. ENNE, 2002.

${ }^{20} \mathrm{Hannerz}$ cita Barth em HANNERZ, Ulf. Cultura/ Complexity. Columbia University Press. New York. 1992, pp.1314.Também Barth, em "A Análise da Cultura nas Sociedades Complexas", indica ter encontrado "ecos dessa perspectiva no trabalho de Hannerz, em suas explorações da antropologia urbana em termos de geração de significados partilhados". Ver BARTH, $F$. "A análise da cultura nas sociedades complexas". In: O guru, o iniciador $e$ outras variações antropológicas. Organização de Tomke Lask. Rio de Janeiro, Contracapa, 2000, p. 127

${ }^{21}$ HANNERZ, op. cit., p. 17. existentes entre os diversos indivíduos que compóem essa rede. Para ele, como para outros autores já abordados neste artigo, tais laços vão permitir que os membros de uma rede, mediante processos interacionais, possam trocar tanto bens em forma de materiais e serviços como bens em caráter simbólico, como informaçōes. Tais trocas, conforme sugere Epstein, passam a ser fundamentais para a configuraçáo de status e prestígio para os membros da rede. ${ }^{19}$

A idéia de fluxos culturais aparece de maneira clara no trabalho de Ulf Hannerz, também uma referência fundamental quando se pensa em sociedade em rede. Segundo Hannerz, partilhando de pontos de vista de Frederick Barth, ${ }^{20}$ as sociedades complexas não podem ser percebidas a partir de uma dicotomia entre a estrutura social e a estrutura cultural, pois os fluxos de informaçóes e idéias, sua materialização e distribuição, são fatores ordenadores e reordenadores das composiçóes sociais, fazendo com que estas sejam marcadas por uma constante mobilidade. Segundo ele, a grande preocupação dos atores sociais envolvidos na construção das sociedades complexas diz respeito à administração desses fluxos de informação, que devem ser materializados, tornados públicos e distribuídos de acordo com as demandas dadas pelas interaçōes sociais.

"As actors and as networks of actors, they are constantly inventing culture or maintaining it, reflecting on it, experimenting with it, remembering it or forgetting it, arguing about it, or passing it on. There are not only static distribuitions of factual knowledge but also different ways of doing things with meanings, likewise unevenly spread out among people and situations. We speak of common sense and consciousness raising, of experts and dilettants, of ritual, play, and critique, of fads and fashions. The covering terms I shift between, in suggesting this processual view of culture as activity, are 'the management of meaning', or 'the management of culture', or just 'cultural management'."21
Hannerz está partindo da idéia de que a cultura não é univocal, e sim um complexo processo polifônico, em constante fluxo de interaçốes. Assim, a cultura teria três dimensões: uma relacionada ao campo das idéias e aos modos de pensar; uma segunda relacionada às formas de externalização dessas idéias, ou seja, como torná-las públicas; e uma terceira relacionada à distribuição social dessas idéias e formas de pensar. Segundo o autor, as Ciências Sociais, de forma geral, tem pensado a cultura privilegiando essa ordem para lidar com o conceito de cultura. Ele propõe uma inversão, indicando que, a seu ver, o caráter distributivo das informaçóes culturais é o mais relevante para entendermos como a cultura é construída a partir das interaçóes e como os fluxos são capazes de gerar as idéias e formas de pensar. Portanto, seu interesse recai sobre os fluxos e as estratégias de gestão cultural ("cultural management"), por parte dos atores e agências sociais, do que deve ser distribuído, em que contexto e a quem, pois o controle sobre tais informaçốes é garantia de poder, prestígio, autoridade e, correlatamente, fundamental na configuraçăo das identidades sociais. Nesse sentido, como agente fundamental nesse processo, a mídia é um poderoso instrumento para o controle do que deve ser informado plenamente, parcialmente ou totalmente omitido.

As reflexōes de Hannerz apontam para a questão central que permeia seu texto: os fluxos culturais são fundamentais na construção de significados públicos para diversas dimensōes do social, dentre elas, a memória. Sua definição de fluxo nos parece de extrema relevância para este trabalho:

The cultural flow thus consists of the externalizations of meanings which individuals produce through arrangements of overt forms, and the interpretations which individuals make of such displays - those of others as well as their own. (...) More precisaly, the flow occurs in time and has directions. As a whole, it is 
endless; externalizations depend on previous interpretations, depending on previous externalizations. And the externalizations occurring now will bring about interpretations which in their turn lead to further externalizations in the future. ${ }^{22}$

Assim, as redes de interação social que podem ser encontradas nas sociedades complexas são também redes de interação cultural, em que as trocas vão se dar em movimentos contínuos entre atores sociais que estarão se relacionando em fronteiras fluidas, que tenderão a se reordenar de acordo com os contextos interativos. Nesse sentido, o trabalho de Frederick Barth, já citado de passagem anteriormente, se apresenta aqui como fundamental.

Barth marcou uma ruptura nos estudos tradicionais acerca das relações interétnicas ao propor uma mudança no paradigma conceitual que indicava que a manutençáo dos limites étnicos seria uma coisa natural, resultante do isolamento. Para Barth, é o contato, ao contrário, que impóe os limites étnicos. Etnicidade seria, portanto, resultado das interaçôes. Os próprios atores, nessas interaçốes, definiriam as fronteiras étnicas. A cultura seria, então, uma constante construção. É fundamental a idéia de processo para demonstrar como se dá constantemente a construção das culturas. Os atores sociais delimitariam as fronteiras sociais e seus critérios identificatórios. ${ }^{23}$

A proposta de Barth para o estudo de grupos étnicos definidos também pode ser ampliada para os estudos acerca de sociedades complexas, como propõe o próprio autor em um texto hoje consagrado. Ele critica as correntes antropológicas que se esforçaram para mapear os padróes culturais das sociedades e se recusaram, conforme sua crítica, a perceber que as mudanças sociais não são uma contradição em face de uma estrutura fechada, mas um indicativo de uma lógica processual, em que os conflitos e transformaçóes devem ser vistos como inerentes e constitutivos das relaçōes, sendo fundamentais para as configuraçōes e reconfiguraçōes dessas sociedades, e não uma ameaça a um padrão estático de cultura.

Essa diversidade desconexa (ao menos aparentemente) de atividades e a mistura do novo com o velho, formando um cenário cultural sincrético, são características desconfortáveis com as quais o antropólogo irá se defrontar em quase todo lugar. Somos treinados a suprimir os sinais de incoerência e de multiculturalismo encontrados, tomando-os como aspectos nãoessenciais decorrentes da modernização, apesar de sabermos que não há cultura que não seja um conglomerado resultante de acréscimos diversificados. ${ }^{24}$

Podemos então dizer que, para Barth, as práticas interativas são o motor da produção da cultura, fazendo com que existam múltiplas possibilidades de arranjos e negociaçóes, dependendo do potencial de contatos e fronteiras que os agentes sociais envolvidos em tais processos podem estabelecer. Nesse sentido, seria impossível perceber a sociedade como uma unidade fechada, com suas características dadas, mas sim como um processo permanente de interaçóes sociais e culturais, em que estas seriam constantemente construídas e desconstruídas, obedecendo a demandas contextuais. Sua proposta metodológica pode ser resumida neste trecho:

Abordar essa áspera cacofonia de vozes autorizadas com a expectativa de que suas mensagens e ensinamentos sejam coerentes, qualquer que seja o sentido que se dê a essa palavra, seria característico de um antropólogo bastante dogmático. Não afirmo que o que é dito e feito năo siga padrăo algum: apenas que devemos esperar uma multiplicidade de padrôes parciais, que interferem uns sobre os outros, e se estabelecem em diferentes graus nas diferentes localidades e nos diferentes campos; e que devemos
${ }^{22} / d e m$, p. 4

${ }^{23}$ Ver BARTH, Fredrik. "Introdution". In: Ethnic Groups and Boundaries: The social organization of cultural difference. London, George Allen \& Unwin, 1969.

${ }^{24}$ BARTH, op. cit., 2000, p. 109. 
${ }^{25} / \mathrm{dem}, \mathrm{p} .120$.

${ }^{26} / d e m$, p. 126-127.

${ }^{27}$ BARTH, op. cit., 2000, pp. 128-129.

28 "A network is made up of pairs of persons who interact with one another in terms of social categories, and who regard each other therefore as approximate social equals, ignoring in this context the slight differences in social status there may be between them. Since it is essentially 'personal' the network allows of many different configurations, and these in turn may provide the basis for a typology of networks". Epstein,

op. cit. , p. 110.

${ }^{29}$ LANDÉ, op. cit., p. xiii. duvidar de toda a afirmaçāo de coerência, salvo quando tiver sido devidamente demonstrada. ${ }^{25}$

Assim, o trabalho do pesquisador deveria ser o de perceber a "estrutura profunda", que se esconderia por sob uma estrutura mais visível, aparentemente padronizada. Na estrutura mais profunda seria possível perceber as múltiplas correntes de tradiçōes culturais (streams) que formariam o que o autor está chamando de pluralismo cultural. Essas culturas deveriam ser percebidas como campos de discurso, com algum grau de coerência, que iriam se constituir e se reproduzir de formas diversas, mas estariam em constante processo de interação, com possibilidades de misturarem-se. Assim,

Devemos abordar as várias correntes que identificarmos, tomando cada uma delas como universo de discurso, e: (i) caracterizar seus padrōes mais destacados; (ii) mostrar como ela se produz e reproduz, e como mantém suas fronteiras; (iii) ao fazê-lo, descobrir o que permite que haja coerência (...). Devemos também identificar os processos sociais pelos quais essas correntes se misturam, ocasionando por vezes interferências, distorçōes e mesmo fusōes. ${ }^{26}$

Em sua busca por reconceitualizar a cultura, Barth propõe um conjunto de asserçôes que devem orientar o trabalho do pesquisador: 1) "O significado é uma relação entre uma configuração ou signo e um observador, e não alguma coisa sacramentada em uma expressão cultural particular"; 2) "Em relaçăo à populaçăo, a cultura é distributiva; compartilhada por alguns e não por outros"; 3) "Os atores estão (sempre e essencialmente) posicionados."; 4) "Eventos são o resultado do jogo entre a causalidade material e a interação social, e conseqüentemente sempre se distanciam das intençôes dos atores individuais." ${ }^{27}$

Antes, porém, para fecharmos esta reflexão, podemos utilizar o conceito de rede proposto por Epstein ${ }^{28}$, juntamente com os pontos abordados até aqui, para apresentar algumas idéias centrais acerca do que estamos chamando aqui de rede: trata-se de um tipo de configuração social que não pode ser considerado um grupo ou agrupamento, por seu caráter fluido e pela ausência de uma unidade entre os membros, pois estes não estāo necessariamente todos em contato uns com os outros, de forma direta, em prol de um objetivo comum, como no caso de um grupo; as relaçóes se dão através de links entre os agentes, de forma interpessoal, marcados por um fluxo de informaçóes, bens e serviços, que irão resultar em processos de interação cujas fronteiras não são estáticas, mas se encontram em permanente construçăo e desconstrução. Nesse sentido, tornase fundamental a conceituação de díades, como proposto por Carl Landé. Segundo ele, "a dyadic relationship, in its social science sense, is a direct relationship involving some form of interaction between two individuals". ${ }^{29}$ Assim, as relaçōes diádicas estariam na base dos grupos não-corporados e, principalmente, das redes sociais, que por ele seriam definidas da seguinte forma:

Larger and more inclusive than dyadic relationship or dyadic noncorporate groups, are social networks. Networks have been defined as 'matrices of social links' or as 'social fields made up of relationship between people'. They include all individuals who find themselves in a given field, and who are within direct or indirect contact reach of each other. That is to say, they include all individuals who are connected directly with at least one other member of network. ${ }^{30}$

A conceituação de díades proposta por Landé foi explorada por Marcos Otávio Bezerra em sua dissertaçáo sobre corrupção e política no Brasil. Assim, ele irá indicar que as relaçôes diádicas "são concebidas como a menor estrutura, visto que por definição envolvem somente duas pessoas". ${ }^{31}$ Uma rede social, portanto, seria uma estrutura maior, composta por uma série de relaçóes diádicas, ou seja, seria formada "por todas aquelas pessoas 
que estão ligadas umas às outras direta ou indiretamente".

Globalização: redes mundiais de socialização

A partir desse esforço conceitual, podemos fazer algumas observaçôes para concluir este artigo e propor algumas reflexóes sobre a idéia de rede associada às sociedades contemporâneas, em especial nos estudos de Comunicação.

Em primeiro lugar, conforme podemos perceber pelas diversas conceituaçôes apresentadas, redes podem ser pensadas em sentidos diversos: ou como sistema de integração entre pessoas, mediante práticas de interação, em um sentido mais social; ou como um sistema de troca de mercadorias e bens materiais, em um sentido mais econômico; ou como trocas de informaçôes e bens simbólicos, em um sentido mais cultural.

Quando vamos pensar, como propôs, por exemplo, M. Castells, as sociedades contemporâneas como sociedades em rede, é preciso levar em consideração todos os sentidos propostos acima. A globalização traz, como um dos seus efeitos mais perceptíveis, a possibilidade de se estabelecer explicitamente sistemas de interação social em rede, em que sujeitos, através de links, participam de trocas econômicas e culturais em amplas escalas, que extrapolam limites espaciais e temporais antes rígidos.

As transformaçōes tecnológicas no campo do transporte e das telecomunicaçóes evidenciam uma alteração nas possibilidades reais de interação social, atuando como um facilitador nas trocas interpessoais, ao vivo ou virtualmente, on-line ou com intervalos temporais. Da mesma forma, a implantação de sistemas de mercado integrados e a produção de cidadanias extraterritoriais, como no caso europeu, também atuam como agilizadores para promover uma maior mobilidade dos sujeitos contemporâneos para além de seus locais de origem. Obviamente, apresentamos essas questóes aqui mais como referências potenciais do que como modificaçōes de fato, já que, como nos lembra Z. Bauman, "turistas" "vagabundos" movem-se (ou não conseguem se mover) de formas diferenciadas dentro desse modelo de sociedade sem fronteiras que se apresenta como a nova ordem mundial. Portanto, sabemos que o mesmo modelo que gera inclusão também é profundamente gerador de exclusóes. O que nos interessa, no entanto, é levantar aqui que características, ao menos potencialmente, são evidenciadas nas sociedades contemporâneas para que elas sejam classificadas como sociedades em rede. Uma dessas características, como indicamos, é a possibilidade de um maior fluxo de pessoas por meio de sistemas de transporte e telecomunicação mais abrangentes.

Da mesma forma, como explica $\mathrm{N}$. Canclini, as práticas comerciais da nova ordem mundial substituem a tradicional distinção entre próprio e alheio. A proliferação de produtos importados nas prateleiras indica, ao menos em tese, a possibilidade cada vez mais acentuada de trocas de bens materiais e mercadorias em escala planetária. Novamente, as facilitaçốes no campo dos transportes e das telecomunicaçōes (permitindo, por exemplo, maior rapidez no envio de mercadorias de lugares distantes tanto quanto no próprio poder do consumidor de agilizar suas compras internacionais por meio da Internet) também são fundamentais para a compreensão do que se entende como uma sociedade em rede.

Por fim, a transmissão de informaçóes e bens simbólicos (desde o dinheiro volatizado nas bolsas de valores integradas até os sistemas de comunicação digitalizados que atuam no mundo inteiro) aponta claramente para a efetivação de um fluxo de comunicação em rede de proporçôes inéditas. Este último aspecto, inclusive, tem sido objeto reflexivo de inúmeros trabalhos no campo da comunicação nas últimas décadas, motivando inúmeras discussóes acerca da relação entre o global e o local no campo da cultura.
${ }^{30}$ LANDÉ, op. cit., p. xxxiii.

${ }^{3 \prime}$ BEZERRA, Marcos Otávio. Corrupção. Um estudo sobre poder público $e$ relações pessoais no Brasil. Rio de Janeiro, Relume-Dumará, ANPOCS, 1995, p. 38.

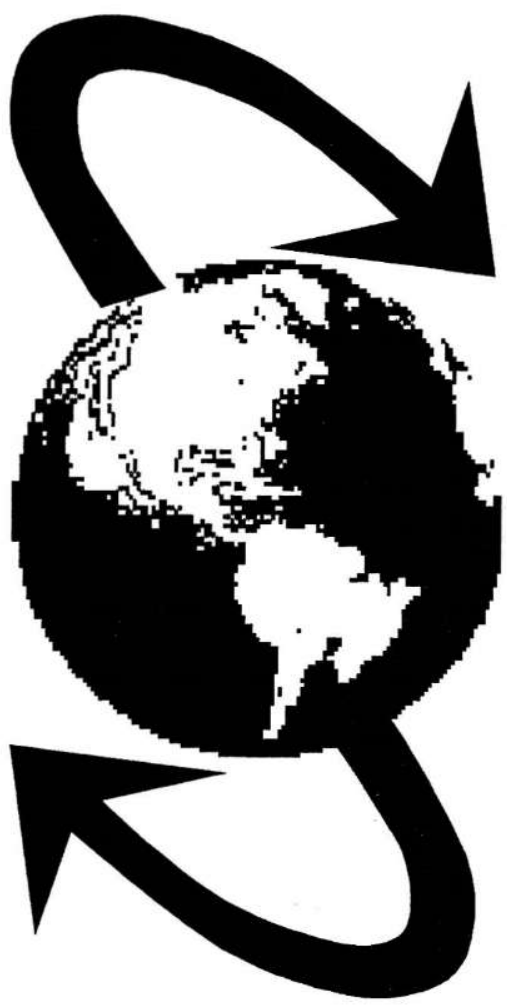


Nāo há dúvida, portanto, de que a idéia de uma sociedade em rede, a partir das transformaçóes citadas acima, é pertinente e adequada aos novos estudos sobre as sociedades contemporâneas. Mas, em um misto de conclusão e inquietação, colocamos aqui duas ordens de problemas que nos parecem importantes de serem levadas em consideração e que, no entanto, têm sido relegadas de uma forma geral.

Em primeiro lugar, gostaríamos de chamar a atenção para a necessidade de refinar o conceito de rede, procurando buscar suas matrizes antes de usá-lo aleatoriamente. Como vimos no texto aqui apresentado, trata-se de um conceito polissêmico, com sentidos diversos. No entanto, ele vem sendo tratado como dado, sem qualquer esforço de localizá-lo historicamente e mesmo de conceituá-lo minimamente. Há, portanto, em nossa compreensão, um uso generalizante do conceito que só tende a esvaziá-lo, em detrimento de sua riqueza e adequação.

Em segundo lugar, exatamente pela ausência de um esforço de historicização, percebemos uma tendência a considerar que o conceito de rede seria adequado somente às sociedades contemporâneas globalizadas. Como vimos no breve levantamento aqui apresentado, o conceito é adequado para qualquer sociedade. $\mathrm{O}$ que poderíamos destacar, no caso contemporâneo, em face do processo de globalização, é a expansão da rede, sua potencialização ampliada $e$ sua explicitação. Nesse sentido, o conceito nos parece muito pertinente, pois trata-se, sem dúvida, de uma conjuntura histórica em que os sentidos propostos para o conceito de rede (interação entre indivíduos, troca de mercadorias e fluxo de informaçóes) estão evidenciados e acabam ocupando um lugar central na configuração cultural, política, econômica e social. Mas é preciso cuidado para não cairmos em um reducionismo histórico, negando o quanto as questōes que hoje nos inquietam fazem parte de um processo de longa duração.
Abstract:

The propose of this article is to indicate some of the main reflections on the network concept, much used in the analyses on the contemporaries societies. The concept is presented in its relation with the flows of good and information.

Key words: network; information flow; contemporaries societies

\section{Bibliografia}

BARNES, J.A. "Class and Committees in a Norwegian Island Parish". Human Relations, $\mathrm{n}^{\circ}$ 7, 1964.

"Redes sociais e processo político". In: FELDMAN-BIANCO, Bela (org.). Antropologia das Sociedades Contemporâneas. São Paulo, Global, 1987.

BARTH, F. "A análise da cultura nas sociedades complexas". In: LASK, Tomke (org.). Oguru, o iniciador e outras variaçōes antropológicas. Rio de Janeiro, Contracapa, 2000.

"Introdution". In: BARTH, F. (org.) Ethnic Groups and Boundaries: The social organization of cultural difference. London, George Allen \& Unwin, 1969.

BAUMAN, Z. Globalização, as conseqüências humanas. RJ, Jorge Zahar, 1999.

BEZERRA, Marcos Otávio. Corrup̧̧ão. Um estudo sobre poder público e relaçóes pessoais no Brasil. Rio de Janeiro, RelumeDumará, ANPOCS, 1995.

BOLTANSKY, Luc. Les cadres, la formation d'un groupe social. Paris, Les Editions de Minuit, 1982.

BOTT, Elisabeth. Familia e rede social. RJ, Francisco Alves, 1976.

CASTELLS, Manuel. A Era da Informaçāo: Economia, Sociedade e Cultura. O poder da Identidade. Volume 2. São Paulo, Paz e Terra, 1992.

CANCLINI, Nestor. Consumidores $e$ Cidadãos. Rio de Janeiro, Ed. UFRJ, 1997. 


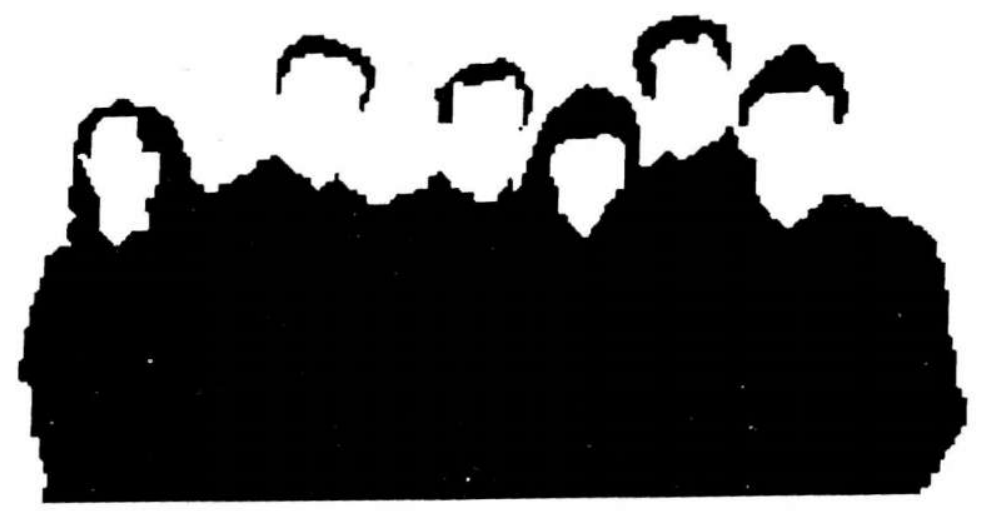

CEBRIÁN, Juan Luis. A rede. SP, Summus, 1999.

ENNE, Ana Lucia. "Lugar, meu amigo, é minha Baixada": memória, identidade e representação social. Tese de Doutorado em Antropologia, PPGAS/MN/UFRJ, 2002. EPSTEIN, A. L.. "The network and urban social organization", In: MITCHELL, J.C. (org.). Social Networks in Urban Situations. Manchester, Manchester University Press, 1969.

HANNERZ, Ulf. Cultural Complexity. Columbia University Press. New York. 1992.

KING, Anthony (org.). Culture, Globalization and the World-System. Hampshire e Londres, The MacMillan Press, 1991.

LANDÉ, Carl. "Introduction: the dyadic basis of clientelism". In: SCHMIDT, Steffen et alii (ed.). Friends, Followers, and Factions. A reader in political clientelism.
Berkeley, University of California Press, 1977.

LEVY, Pierre. Ciberbultura. São Paulo, Editora 34, 1999.

MAYER, Adrian. "A importância dos 'quase-grupos' no estudo das sociedades complexas". In: FELDMAN-BIANCO, Bela (org.) Antropologia das sociedades contemporâneas. SP, Global, 1987.

MCLUHAN, Marshall. Os meios de comunicação como extensōes do homem. Sāo Paulo, Cultrix, 1964.

MITCHELL, J.C. Social Network in Urban Situations. Manchester University Press, 1969.

MORAES, Dênis de (org.). Globalização, mídia e cultura contemporânea. Campo Grande, Letra Livre, 1997.

SANTOS, Milton.. Por uma outra globalização. Rio de Janeiro, Record, 2000. SIMMEL, G. "The Triad”. In: The Sociology of Georg Simmel. London, The Free Press, 1950 . 